\title{
Can climate trends be calculated from reanalysis data?
}

\author{
Lennart Bengtsson ${ }^{1}$ \\ Environmental Systems Science Centre, Reading, UK
}

Stefan Hagemann

Max-Planck-Institute for Meteorology, Hamburg, Germany

Kevin I. Hodges

Environmental Systems Science Centre, Reading, UK

Received 14 January 2004; revised 23 March 2004; accepted 14 April 2004; published 9 June 2004.

[1] Several global quantities are computed from the ERA40 reanalysis for the period 1958-2001 and explored for trends. These are discussed in the context of changes to the global observing system. Temperature, integrated water vapor (IWV), and kinetic energy are considered. The ERA40 global mean temperature in the lower troposphere has a trend of $+0.11 \mathrm{~K}$ per decade over the period of 1979-2001, which is slightly higher than the MSU measurements, but within the estimated error limit. For the period 19582001 the warming trend is $0.14 \mathrm{~K}$ per decade but this is likely to be an artifact of changes in the observing system. When this is corrected for, the warming trend is reduced to $0.10 \mathrm{~K}$ per decade. The global trend in IWV for the period $1979-2001$ is $+0.36 \mathrm{~mm}$ per decade. This is about twice as high as the trend determined from the Clausius-Clapeyron relation assuming conservation of relative humidity. It is also larger than results from free climate model integrations driven by the same observed sea surface temperature as used in ERA40. It is suggested that the large trend in IWV does not represent a genuine climate trend but an artifact caused by changes in the global observing system such as the use of SSM/I and more satellite soundings in later years. Recent results are in good agreement with GPS measurements. The IWV trend for the period 1958-2001 is still higher but reduced to $+0.16 \mathrm{~mm}$ per decade when corrected for changes in the observing systems. Total kinetic energy shows an increasing global trend. Results from data assimilation experiments strongly suggest that this trend is also incorrect and mainly caused by the huge changes in the global observing system in 1979. When this is corrected for, no significant change in global kinetic energy from 1958 onward can be found. INDEX TERMS: 1610 Global Change: Atmosphere (0315, 0325); 3309 Meteorology and Atmospheric Dynamics: Climatology (1620); 3337 Meteorology and Atmospheric Dynamics: Numerical modeling and data assimilation; KEYWORDS: trend, reanalysis, climate, water vapor

Citation: Bengtsson, L., S. Hagemann, and K. I. Hodges (2004), Can climate trends be calculated from reanalysis data?, J. Geophys. Res., 109, D11111, doi:10.1029/2004JD004536.

\section{Introduction}

[2] A point of concern in the assessment of climate change is the lack of long-term climate records from the free atmosphere. This is particularly the case before World War II when our knowledge of the atmosphere was essentially based on observations from the surface of the Earth. The radiosonde network, which was built up after the end of World War II, was essentially confined to the extra-tropical regions of the Northern Hemisphere (NH). However, in the Tropics and the Southern Hemisphere (SH) the upper air

${ }^{1}$ Also at Max-Planck-Institute for Meteorology, Hamburg, Germany.

Copyright 2004 by the American Geophysical Union. 0148-0227/04/2004JD004536\$09.00 network was so sparse, until the availability of data from satellites, that systematic analyses and predictions were severely hampered or not even feasible [Miyakoda et al., 1969]. A global observing system was established in 1979 following the Global Weather Experiment with the implementation of a comprehensive space based observing system. It is thus important to note that the global observational records through the depth of the atmosphere prior to 1979 have considerable deficiencies.

[3] During the last decade major attempts have been made to overcome this obstacle and to create comprehensive climate records for longer periods going back further in time. A preferred method to reconstruct the three-dimensional state of the atmosphere of the past is to use the same methodology as in Numerical Weather Prediction (NWP) [Bengtsson and Shukla, 1988]. In this way the available 
observations are reanalyzed with advanced data-assimilation techniques to provide a consistent initial state for the next short term forecast thus generating a continuous stream of three-dimensional fields of meteorological variables. Several reanalysis data sets have recently been produced and made available for climate and weather prediction studies, for example the European Centre for MediumRange Weather Forecasts (ECMWF) 15 year reanalysis (ERA15) [Gibson et al., 1997]; the National Center for Environmental Prediction, National Center for Atmospheric Research (NCEP/NCAR) reanalysis [Kalnay et al., 1996; Kistler et al., 2001] and the NASA Goddard Earth Observing System 1 (GEOS1) reanalysis [Schubert et al., 1993]. The longest of them, the NCAR/NCEP reanalysis, covers about 55 years. Here we investigate the ECMWF 40 year reanalysis (ERA40) data set, which covers the period 19582001 [Simmons and Gibson, 2000].

[4] The space and time resolution of the generated data determined by the model are independent of the number of observations, since areas void of observations will be filled with dynamically and physically consistent model generated information. Although the reanalysis will provide data sets for any period of time it is evident that their usefulness crucially depends on the quality and distribution of the observations in time and space. At the same time we must note that this is by far the most accurate way to interpolate data in time and space as well as a superior way to obtain dynamical consistency between different atmospheric variables. It is also more representative as it provides an opportunity to eliminate local effects such as caused for example by urbanization [Kalnay and Cai, 2003].

[5] In this paper the extent to which the ERA40 data set can be used to identify longer-term trends is explored. Data assimilation methods are generally efficient in reducing random errors while biases in the observations are difficult to eliminate. A bias changing in time can thus introduce a fictitious trend without being eliminated by the data assimilation system. A fictitious trend can be generated by the introduction of new types of observations such as from satellites and by instrumental and processing changes in general. Fictitious trends could also result from increases in observational coverage since this will affect systematic model errors. Assume, for example, that the assimilating model has a cold bias in the upper troposphere which is a common error in many general circulation models (GCM). As the number of observations increases the weight of the model in the analysis is reduced and the bias will correspondingly become smaller. This will then result in an artificial warming trend.

[6] It is of particular interest to ascertain how the large changes in the global atmospheric observing system in the 1970 s may have affected the assessment of long-term climate trends. This has been investigated by making use of a series of assimilation experiments [Bengtsson et al., 2004], whereby different forms of the observing system have been explored by systematically excluding data from the full ERA40 observational database. By exploring the differences between the full observing system (representing the situation from the 1980s onward) and the reduced system (representing the system in the 1960s and 1970s) a correction factor is determined, which has been used to re-estimate the long-term trends.
[7] In this paper the main interest is on the large-scale aspects of climate with the main focus of the study on the long-term evolution of global tropospheric temperature, the vertically integrated water vapor (IWV) and the vertically integrated kinetic energy. As our index of the large-scale atmospheric temperature, we calculated from the ERA-40 data the deep-layer temperature of the lower troposphere as estimated from Microwave Sounding Unit (MSU) observations by Christy et al. [2003].

[8] The paper continues with a description of the setup for the observing system experiments using the ERA40 system. In section 3 the results for the temperature trend calculations are presented, section 4 deals with the IWV trend and the trend of the kinetic energy is considered in section 5 . The overall results are then discussed in section 6 .

\section{Data and Experimental Description}

[9] A series of different methods have been used to validate the long-term trends in ERA40. We compare the temperature trend for the period 1979-2001 with observed MSU data and with GCM integrations driven by observed sea surface temperature (SST). The model used is the recently developed European Center/Hamburg 5 (ECHAM5) model integrated at a spectral resolution of triangular truncation T106 [Roeckner et al., 2003]. An intercomparison of the observed MSU with a number of other data sets including the NCAR/NCEP reanalysis has been undertaken by Christy et al. [2003]. We compare the IWV with model simulations (see above) and with the NCAR/NCEP data set.

[10] In order to assess the longer term trends for 19582001, which includes the pre-satellite period, a special data assimilation with the ERA40 system [Bengtsson et al., 2004] has been used covering three periods, DecemberFebruary (DJF) 1990/91, June-August (JJA) 2000 and DJF $2000 / 01$. In this experiment all satellite observations have been excluded in order to mimic the pre-satellite observing system. This will be called the NOSAT experiment. The IWV for ERA40 and the NOSAT assimilation is validated with data from 160 globally distributed Global Positioning System (GPS) stations from the international GPS Service (IGS). This intercomparison covers July 2000 and January 2001. The methodology of the intercomparison with GPS measurements is given by Hagemann et al. [2003].

\section{Temperature Trends}

[11] Time series of deep-layer temperatures derived from microwave emissions exist for almost 25 years. They have been compiled from 11 NOAA polar orbiting satellites and from two types of measuring instruments (MSU until September 1998, thereafter advanced microwave sounding unit (AMSU)). The data set has undergone several reassessments [Christy et al., 1998, 2000], the latest recently published by Christy et al. [2003] where accuracy estimates for the MSU data were also provided. We expect these error estimates to represent a lower bound of the accuracy since all errors in the estimates have been associated with the MSU data as the reference data used for their intercomparison study (such as radiosonde data) were considered to be error free. 


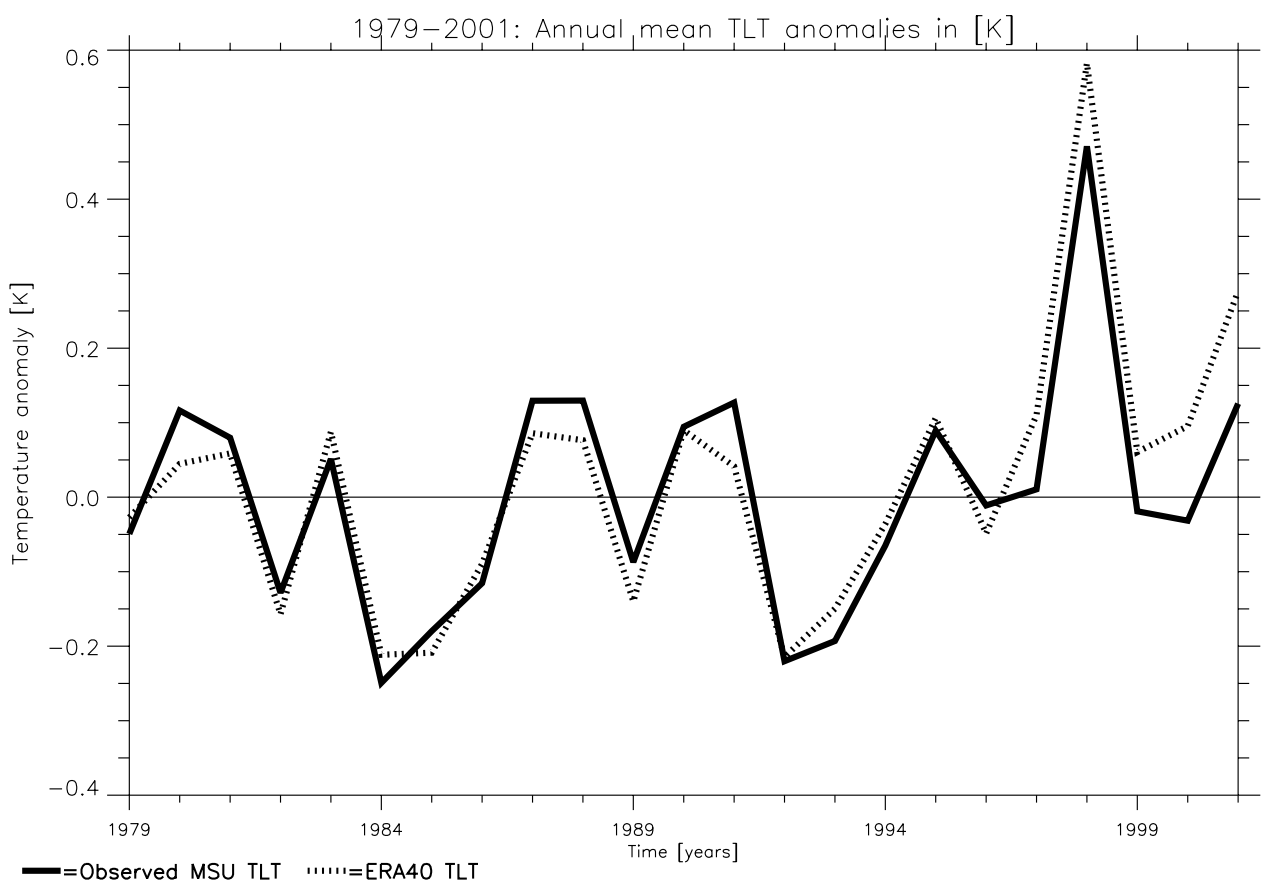

Figure 1. Lower tropospheric temperature, TLT, from MSU measurements (solid line) and calculated from ERA40 (dashed) for the period 1979-2001.

[12] For the 1979-2001 period the MSU and ERA40 temperature of the lower troposphere (TLT) are shown in Figure 1. The equivalent TLT has been calculated from the ERA40 data following the method used by Stendel and
Bengtsson [1997]. The ERA40 data show a slightly stronger warming trend in the lower troposphere than the MSU data. The calculated anomaly trend for the TLT in ERA40 is $+0.11 \mathrm{~K}$ per decade versus $+0.06 \mathrm{~K}$ per decade for MSU.

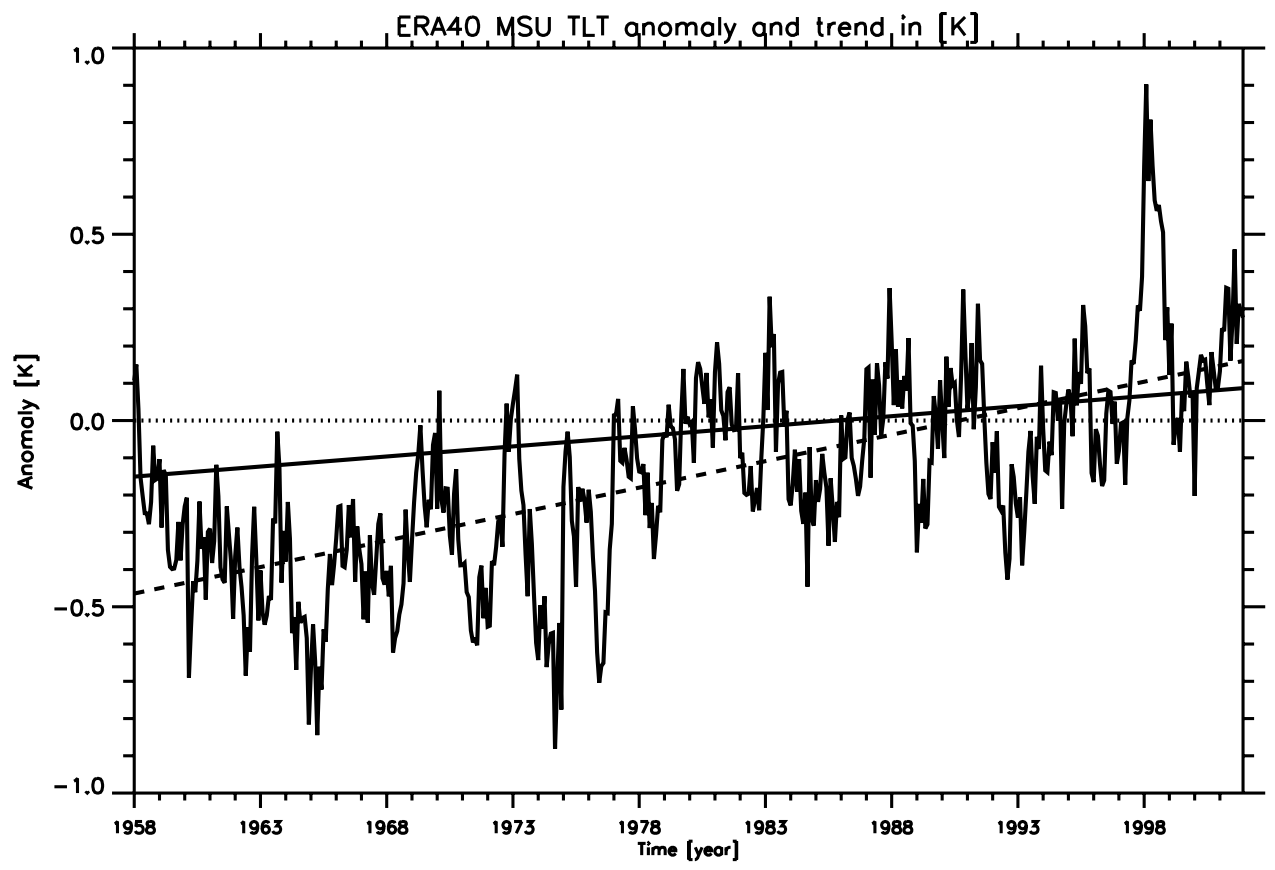

Figure 2. TLT calculated from ERA40 for the period 1958-2001. The dashed line shows the corresponding warming trend. The full line indicates a corrected warming trend obtained by adding a factor to the data for the period 1958-1972 obtained from the difference between ERA40 and the NOSAT experiment, and by excluding data for the years $1972-1978$. See color version of this figure in the HTML. 


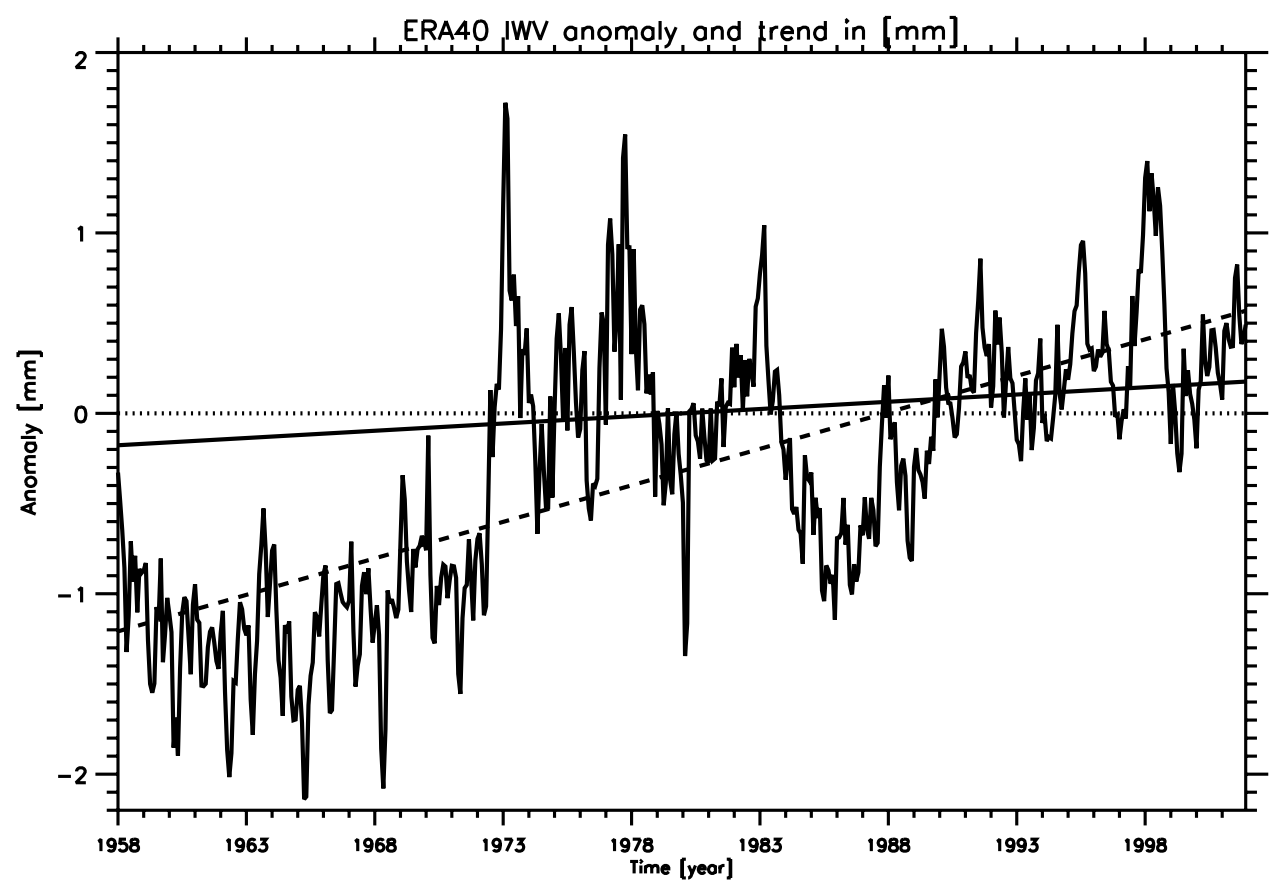

Figure 3. Vertically integrated water vapor, IWV, of ERA40 for the period 1958-2001. The dashed line shows an increasing trend. The full line indicates a corrected trend obtained by adding a factor to the data for the period 1958-1972 obtained from the difference between ERA40 and the NOSAT experiment, and by excluding data for the years 1972-1978. See color version of this figure in the HTML.

The larger trend in ERA40 is still within the estimated error range as given by Christy et al. [2003] but likely overestimated. We will be discuss this further in section 6 .

[13] For the longer period 1958-2001 results are shown in Figure 2 which show that in ERA40 the TLT warming trend $(0.14 \mathrm{~K}$ per decade) is higher than for the period 1979-2001. We have excluded data for the period 19721978 as we believe the influence of vertical temperature profile radiometer (VTPR) data in ERA40 in these years have been detrimental for the trend calculations of TLT and IWV. While the ERA40 TLT trend is just within the error bars of the observed MSU temperatures for the time period 1979-2001 the question is whether the even larger trend for the longer period $1958-2001$ is reliable. No MSU data are available for the earlier period of 1958-78. Thus the reliability of the trend has to be judged in another way.

[14] First it should be noted that for the 1979-2001 period the SST trend at $+0.11 \mathrm{~K}$ per decade is the same as for the TLT, while for the extended 1958-2001 period the SST trend $(+0.08 \mathrm{~K}$ per decade) is distinctly smaller than the TLT trend ( $+0.14 \mathrm{~K}$ per decade). The SST and the TLT trends are expected to broadly be similar because of the strong coupling to the tropical ocean [Su et al., 2003]. The results suggests that the calculated TLT trend for the period prior to 1979 is too large. The data used to calculate the TLT trend are expected to be less accurate than the SST data because of lower observational density and higher-frequency variability of the atmospheric data. Similarly, but presumably to a smaller degree, the SST trend is also influenced by the fact that SST analyses have become more accurate after 1979 with the introduction of satellite observations.

[15] Could the large TLT trend be an artifact of the changes in the global observing system? These were substantial in the late 1970 s with the change from a terrestrial based system to a system including satellite observations with global coverage. To investigate such a bias recent data-assimilation experiments with ERA40 [Bengtsson et al., 2004] were considered. These experiments have been designed to explore the characteristic differences in the ERA40 data for the 1979-2001 period when selected observing systems are omitted.

[16] In the NOSAT experiment (all satellite data removed) TLT was 0.16 degree $\mathrm{K}$ lower than for the ERA40 control for the three experimental periods suggesting that the ERA40 data using the observing system prior to 1972 may have had a systematic cold bias in the troposphere. Assuming that such a bias would be representative for the whole period 1958-1972, the effect of removing the satellite data would be to reduce the warming trend to a value similar to the period after 1979 and also to become more in agreement with the overall SST trend. A more detailed estimate would require the data-assimilation to be repeated for the whole period without the satellite and other novel observing systems. Such a calculation is presently not feasible to undertake, but is strongly recommended for the future. Nevertheless, there are indications that the ERA40 tropospheric warming trend for 1958-2001 is too large. A more credible warming trend is about $40 \%$ less (see Figure 2).

\section{Integrated Water Vapor Trends}

[17] The IVW calculated from the ERA40 data is shown in Figure 3. The trend in IWV for the whole period 19582001 (years $1972-78$ are excluded) is $+0.41 \mathrm{~mm}$ per decade. For the years with more comprehensive observations $1979-2001$ the trend is $+0.36 \mathrm{~mm}$ per decade. 
Table 1. Decadal Trends for $1979-2001^{\mathrm{a}}$

\begin{tabular}{lcccc}
\hline & TLT, K & SST, K & IWV, mm & IWV/TLT, mm/K \\
\hline MSU & 0.06 & 0.11 & $\ldots$ & $\ldots$ \\
ERA40 & 0.11 & 0.11 & 0.36 & 3.15 \\
ECHAM5 (T106L19) & 0.18 & 0.10 & 0.25 & 1.37 \\
ECHAM5 (T106L31) & 0.19 & 0.10 & 0.29 & 1.54 \\
NCEP/NCAR & $\ldots$ & $\ldots$ & -0.06 & $\ldots$ \\
\hline
\end{tabular}

${ }^{\mathrm{a}}$ For the ECHAM5 simulations, trends are valid for 1979-1999.

[18] For the latter period the ERA40 IWV trend is compared with two simulation studies with the high resolution ECHAM5 model at two different vertical resolutions. The ECHAM5 model is driven by the same SST values but with no changes in greenhouse gases and atmospheric aerosols. The warming trends in the two ECHAM5 simulations are very similar but larger than both ERA40 and the observed MSU (Table 1), yet the trend in IWV is smaller. The tropospheric warming trends in the two ECHAM 5 simulations are $+0.18 \mathrm{~K}$ per decade and $+0.19 \mathrm{~K}$ per decade, respectively. The changes in IWV for the period 19792001 for the two model simulations are $+0.25 \mathrm{~mm}$ per decade and $+0.29 \mathrm{~mm}$ per decade respectively, following closely the Clausius-Clapeyron relation. This is less than the analyzed IWV trend of $+0.36 \mathrm{~mm}$ per decade in ERA40 when in fact we would expect the opposite in view of the larger warming trend in ECHAM 5 (see Table 1).

[19] The increase of IWV in ECHAM5 is 6-7\% in water vapor per Kelvin, broadly following the Clausius-Clapeyron relation [Trenberth et al., 2003], this is almost twice as large as ERA40 for the 1979-2001 period. A similar calculation for the period 1958-2001 suggests an even faster increase than in 1979-2001 (Table 2). Again, this could be an artificial increase caused by the changes in the observing system. The IWV in the NOSAT experiment is actually $1.1 \mathrm{~mm}$ (4.3\%) less than in ERA40 (Table 3). The most likely explanation is that the reduced observing system in NOSAT results in an underestimation of IWV due to the enhanced influence of the model bias [Bengtsson et al., 2004].

[20] To explore the discrepancy between the ERA40 and the NOSAT experiment we compare IWV with in situ GPS measurements for the month of July 2000 and January 2001 [Hagemann et al., 2003]. The results are summarized in Table 4 and Figure 4 and show that in most areas ERA40 agrees better with the GPS observations than does the NOSAT experiment. Furthermore, the NOSAT experiment has a dry bias in almost all areas. It is also dryer than ERA40 except over the central United States during winter, where ERA40 has a slight dry bias compared to the GPS derived IWV [Hagemann et al., 2003]. Because of the heterogeneous distribution of GPS measurements it is not possible to determine a reliable value of the typical global average but the indications are that the NOSAT assimilation underestimates IWV. The IWV of ERA40 may also be underestimated but less than in the NOSAT assimilation. The NCAR/NCEP has also been explored for the IWV trend and shows negative trends for both periods. We believe this

Table 2. Decadal Trends for $1958-2001$

\begin{tabular}{lcccc}
\hline & TLT, $\mathrm{K}$ & $\mathrm{SST}, \mathrm{K}$ & IWV, $\mathrm{mm}$ & IWV/TLT, $\mathrm{mm} / \mathrm{K}$ \\
\hline ERA40 & 0.14 & 0.08 & 0.41 & 2.85 \\
ERA40/corr & 0.10 & 0.08 & 0.16 & 1.55 \\
NCEP & $\ldots$ & $\ldots$ & -0.24 & $\ldots$ \\
\hline
\end{tabular}

Table 3. Globally Averaged IWV for ERA40 and the NOSAT Experiment $^{\mathrm{a}}$

\begin{tabular}{lcccc}
\hline & DJF 1990/91 & JJA 2000 & DJF 2000/01 & Mean Difference \\
\hline ERA40 & 24.0 & 26.7 & 24.0 & \\
NOSAT & 23.2 & 25.3 & 22.8 & $-1.1(-4.3 \%)$ \\
\hline
\end{tabular}

${ }^{\mathrm{a}}$ Unit of measure is millimeters of column water.

is not credible given the overall warming trend both in SST and TLT (Table 1).

\section{Kinetic Energy}

[21] Because of the sparsity of radiosondes and the difficulty in systematically observing kinetic energy of the global atmosphere from space observations, the only realistic option for determining the kinetic energy is to calculate it from reanalysis data sets. Here the ERA40 data set is used. The same algorithm has been used to compute the vertically integrated kinetic energy for ERA40 and the NOSAT experiment.

[22] The total kinetic energy $K$ is computed from the ERA40 data as an integral with respect to pressure $p$ over all atmospheric levels:

$$
K=1 / 2 \int_{0}^{p_{0}} \rho\left(u^{2}+v^{2}\right) d p
$$

where $u$ and $v$ are the zonal and meridional wind components and $\rho$ is the air density. The annually averaged values of $K$ are shown in Figure 5 and vary between $1.50 \mathrm{MJ} \mathrm{m}^{-2}$ and $1.69 \mathrm{MJ} \mathrm{m}^{-2}$. A closer inspection shows that the values tend to fall into two groups with smaller values before 1979 and larger values thereafter. No significant trend can be identified for the period 1958-1978 and for 1979-2001, respectively. It is strongly suggested that the increase in 1979 is due to changes in the observing system introduced initially for the Global Weather Experiments. This is also supported by the NOSAT experiment where the kinetic energy is similar to what was analyzed before 1979. The largest changes are in the SH extra-tropics where every single year after 1979 had higher kinetic energy than the years before 1979 (not shown). The sudden change in kinetic energy for the $\mathrm{NH}$ extra-tropics is smaller but still significant. The estimated kinetic energy increase in 1979 is about $4 \%$ compared to $7 \%$ for the SH extra-tropics. The largest changes occur in DJF in both hemispheres with $6 \%$ and $11 \%$ respectively. The kinetic energy increase in the tropics is smaller (about $2 \%$ with proportionally larger interannual variations. Maximum values are found during positive El Niño Southern Oscillation (ENSO) events.

[23] The NOSAT experiment supports this finding as can be seen in Table 5. The global kinetic energy in the NOSAT is about $4 \%$ less than in ERA 40 which is close to the mean difference between the years 1958-1978 (without satellites) and 1979-2001, respectively. This confirms the notion that the positive kinetic energy trend for the period 1958-2001 is an artifact caused by the changes in the global observing system.

\section{Discussion}

[24] The temperature trend of the lower troposphere for the period 1979-2001 as computed from ERA40 expressed 
Table 4. Regional Station Averages of Relative IWV Bias for ERA40 and NOSAT ${ }^{\mathrm{a}}$

\begin{tabular}{|c|c|c|c|c|c|c|c|c|}
\hline \multirow[b]{2}{*}{ Region } & \multirow[b]{2}{*}{ Latitude, deg } & \multirow[b]{2}{*}{ Longitude, deg } & \multicolumn{3}{|c|}{ January 2001} & \multicolumn{3}{|c|}{ July 2000} \\
\hline & & & $N_{S t}$ & ERA40 & NOSAT & $N_{S t}$ & ERA40 & NOSAT \\
\hline North America & $30^{\circ} \mathrm{N}-90^{\circ} \mathrm{N}$ & $170^{\circ} \mathrm{W}-50^{\circ} \mathrm{W}$ & 25 & -3.51 & -1.64 & 22 & -1.33 & -3.47 \\
\hline Central USA/Canada & $35^{\circ} \mathrm{N}-65^{\circ} \mathrm{N}$ & $120^{\circ} \mathrm{W}-70^{\circ} \mathrm{W}$ & 12 & -9.94 & -9.99 & 12 & 0.18 & 0.4 \\
\hline Central America & $5^{\circ} \mathrm{N}-30^{\circ} \mathrm{N}$ & $115^{\circ} \mathrm{W}-55^{\circ} \mathrm{W}$ & 4 & -4.42 & -5.49 & 4 & -1.53 & -14.64 \\
\hline South America & $55^{\circ} \mathrm{S}-10^{\circ} \mathrm{N}$ & $85^{\circ} \mathrm{W}-30^{\circ} \mathrm{W}$ & 3 & -0.98 & -4.61 & 3 & -4.59 & -8.58 \\
\hline Southern Africa & $40^{\circ} \mathrm{S}-5^{\circ} \mathrm{N}$ & $5^{\circ} \mathrm{E}-55^{\circ} \mathrm{E}$ & 3 & -1.52 & -2.21 & 2 & -6.76 & -6.9 \\
\hline Europe & $35^{\circ} \mathrm{N}-75^{\circ} \mathrm{N}$ & $15^{\circ} \mathrm{W}-45^{\circ} \mathrm{E}$ & 42 & 1.63 & 0.33 & 35 & -1.00 & 0.36 \\
\hline Baltic Sea catchment & $50^{\circ} \mathrm{N}-70^{\circ} \mathrm{N}$ & $5^{\circ} \mathrm{E}-40^{\circ} \mathrm{E}$ & 19 & 1.94 & -2.12 & 16 & -0.22 & -2.07 \\
\hline Central Europe & $42^{\circ} \mathrm{N}-55^{\circ} \mathrm{N}$ & $5^{\circ} \mathrm{E}-30^{\circ} \mathrm{E}$ & 20 & 1.62 & 0.22 & 17 & -2.66 & -1.15 \\
\hline Mediterranean Sea & $30^{\circ} \mathrm{N}-45^{\circ} \mathrm{N}$ & $10^{\circ} \mathrm{W}-40^{\circ} \mathrm{E}$ & 13 & -1.17 & -1.37 & 11 & 4.35 & 5.25 \\
\hline Siberia & $50^{\circ} \mathrm{N}-80^{\circ} \mathrm{N}$ & $60^{\circ} \mathrm{E}-180^{\circ} \mathrm{E}$ & 7 & -24.93 & -31.26 & 5 & 4.81 & 0.58 \\
\hline Saudi Arabia & $10^{\circ} \mathrm{N}-35^{\circ} \mathrm{N}$ & $30^{\circ} \mathrm{E}-60^{\circ} \mathrm{E}$ & 4 & -2.56 & -7.47 & 3 & 10.75 & -3.83 \\
\hline Southern Asia & $0^{\circ} \mathrm{N}-35^{\circ} \mathrm{N}$ & $60^{\circ} \mathrm{E}-150^{\circ} \mathrm{E}$ & 4 & 3.07 & -9.31 & 4 & 3.70 & -7.07 \\
\hline Tropical Indian/Pacific Oceans & $15^{\circ} \mathrm{S}-15^{\circ} \mathrm{N}$ & $60^{\circ} \mathrm{E}-180^{\circ} \mathrm{E}$ & 8 & 0.23 & -9.11 & 8 & 0.99 & -10.3 \\
\hline Australia & $45^{\circ} \mathrm{S}-10^{\circ} \mathrm{S}$ & $110^{\circ} \mathrm{E}-150^{\circ} \mathrm{E}$ & 7 & -2.38 & -4.38 & 8 & -4.21 & -8.44 \\
\hline Australia and surroundings & $60^{\circ} \mathrm{S}-0^{\circ} \mathrm{S}$ & $90^{\circ} \mathrm{E}-180^{\circ} \mathrm{E}$ & 12 & -2.63 & -6.18 & 12 & -4.08 & -8.78 \\
\hline
\end{tabular}

${ }^{a}$ ERA40 and NOSAT bias values are in percent normalized by IWV derived from GPS data. $N_{S t}$ is number of valid GPS stations within the region. For further information, see text.

in terms of microwave emission has been shown slightly higher than the MSU observations but within the limit of the estimated accuracy.

[25] By comparing the TLT between ERA40 and the NOSAT experiment for the period DJF 1990/91 and for the periods JJA 2000 and DJF 2000/01 respectively, the relative warming is higher in the latter period than in the former. This suggest that the additional satellite observations in ERA40 in the latter period (such as more extensive use of the Special Sensor Microwave Imager (SSM/I) data) may have caused an artificial warming trend suggesting that the ERA40 TLT trend at $+0.11 \mathrm{~K} /$ decade is on the high side. This is in agreement with Christy et al. [2003] but much smaller than the recent findings by Vinnikov and Grody [2003], who suggest that the TLT trend is $(+0.22-$ +0.26 /decade) and thus closer to the IPCC results for the near surface temperature trend.

[26] The lower tropospheric temperature trend for the longer period, 1958-2001, is influenced by the major changes in the observing system which occurred at the end of the 1970s. Because the assimilating model has a cold bias in the troposphere the analysis with a reduced network mimicking the terrestrial network of the 1960s and 1970s is colder than the analysis of the 1980s and 1990s based on a more comprehensive observational data coverage. When the bias is corrected for the terrestrial network the warming trend is reduced by $40 \%$ and is in closer agreement with the SST trend. The correction factor was obtained by reassimilating the terrestrial part only of the complete ERA40 system for the three seasons of DJF 1990/91, DJF 2000/2001 and JJA 2000. The systematic differences are rather similar for the three seasons. However, this can only be considered as a preliminary estimate because of the short periods involved and because of the fact that the terrestrial system has also changed. A possible contribution from changes in the terrestrial system cannot be excluded in spite of radiosonde bias correction in ERA40 (S. Uppala, ECMWF, personal communication), but it is considered to be of secondary importance. The main cause of the large warming trend in ERA40 is suggested to be an artifact caused by the large changes in the observational coverage at the end of the 1970s and the corresponding reduction in the cold bias emanating from the first guess of the assimilating model.

[27] The ERA40 trend in IWV for the period 1979-2001 is $+0.36 \mathrm{~mm}$ per decade or $3.15 \mathrm{~mm}$ increase per degree Kelvin of TLT. This would correspond to an increase of global IWV of $12 \%$ per degree warming of TLT, which is about twice as high as could be estimated from the Clausius-
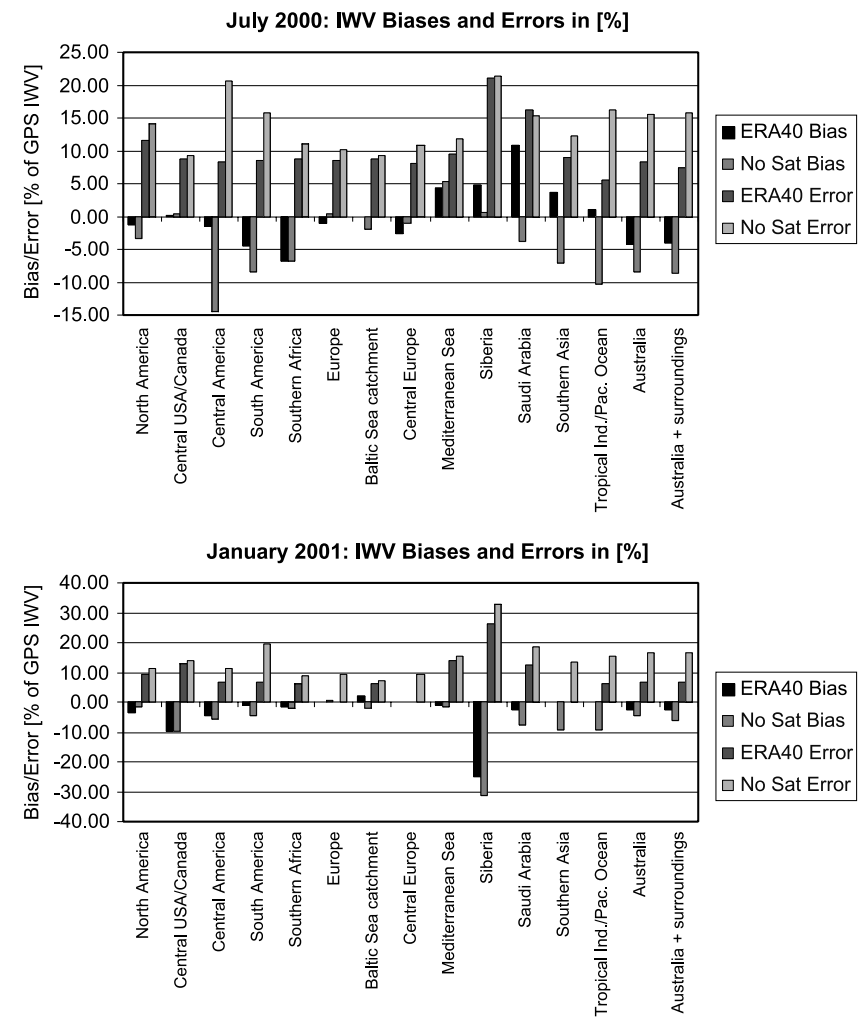

Figure 4. IWV bias and total error for (top) July 2000 and (bottom) January 2001 from comparison with GPS measurements in selected areas (see Table 4). Darker shaded vertical bars indicate the results from ERA40; lighter shaded bars indicate results from the NOSAT experiment. Note the dry bias, particularly in the NOSAT experiment. 
ERA 40: Total kinetic energy for 1958 - 2001

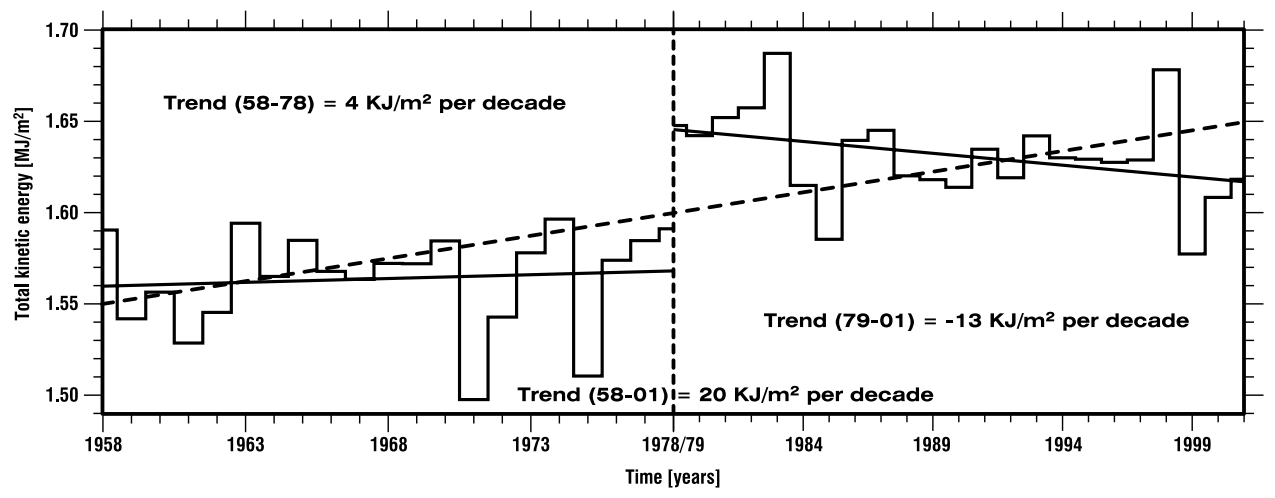

Figure 5. Total kinetic energy, K, annually averaged, calculated from ERA40 for the period 19582001. Figure 5 is in two parts, the first showing the years 1958-1978, the second part showing the years 1979-2001. A trend line is indicated for the whole period as well as separately for the two periods. See color version of this figure in the HTML.

Clapeyron relation [Trenberth et al., 2003]. An increase in IWV of about $6 \%$ per degree Kelvin is also what is obtained from GCM integrations forced by observed SST (Table 1). This suggests that the IWV trend is too high, presumably due to changes in the observing system during the period. Table 3 shows that the assimilation experiment with reduced observations has lower IWV. The largest contribution to IWV comes from the satellite observations. We calculated the contribution from SSM/I for December 1990 and found a small increase of $0.5 \%$ in IWV compared to NOSAT. Another possible cause could be the large increase in the number of satellite soundings in the latter part of the period. A comparison with GPS data [Hagemann et al., 2003] shows a very good agreement with ERA40 IWV at many locations, but the network of GPS stations is too sparse to identify any global bias. However, indications are that the NOSAT system underestimates IWV and the complete ERA40 system is in better agreement with the independent GPS measurements.

[28] The IVW trend for 1958-2001 is judged to be too large. This is assumed to be due to changes in the observing system. Table 3 shows that the NOSAT assimilation is markedly lower for all the three experimental periods. The reduction is proportionally larger for the two later periods in 2000 and 2001 than in 1990/91. Correcting for the mean of the three periods brings the average trend to $+0.16 \mathrm{~mm}$ per decade. With this correction a value of $1.55 \mathrm{~mm}$ per Kelvin is obtained which again is consistent with the ClausiusClapeyron relation.

[29] For the period 1958-2001 there is no indication of any noticeable trend in global kinetic energy. The increasing trend in ERA40 is artificial. Firstly, there is a marked incremental increase between 1978 and 1979 coinciding with the introduction of the global satellite observing system. The largest change occurs in the SH extra-tropics. Here there is not a single year in 1958-1978 which has more energy than any year in 1979-2001. Secondly, the global kinetic energy in the NOSAT experiment is reduced by almost the same amount as the differences between the latter and the former period.

[30] This study shows that there is a great deal of uncertainty in the calculation of trends from present reanalyses data. This highlights the requirement for an homogeneous observing system for reliable trends to be computed, but that some corrections appear feasible through a careful evaluation of each phase of change in the global observing system. Such an evaluation will also have to consider the effect of long-term change in the instruments that also may introduce additional artificial trends.

[31] As has been pointed out many times previously, for example, Goody et al. [2002] and Trenberth et al. [2002], the present observing system, which was essentially set up to support weather forecasting, is not directly suitable for climate monitoring. To reanalyze the atmosphere with a frozen assimilation system goes some way toward alleviating the situation, but the many changes in the observing system and the existence of systematic errors in the assimilating model is an additional severe limitation. As has been suggested here a more meaningful estimate of trends can be achieved by calculating the impact of adding new observations and to use this as a correction in re-calculating the trends.

[32] Because of limited resources this study must be seen as a very preliminary one where only the effect of the major

Table 5. Kinetic Energy in ERA40 and in NOSAT Experiments ${ }^{\mathrm{a}}$

\begin{tabular}{lcc}
\hline Region & ERA40 & NOSAT \\
\hline & DJF $1990 / 91$ & \\
Global & 1.75 & 1.68 \\
NH & 2.73 & 2.72 \\
SH & 2.18 & 1.98 \\
Tropics & 1.06 & 1.03 \\
& & \\
Global & JJA 2000 & 1.60 \\
NH & 1.60 & 1.04 \\
SH & 1.04 & 3.42 \\
Tropics & 3.48 & 0.97 \\
& 0.95 & \\
Global & & 1.68 \\
NH & DJF $2000 / 01$ & 2.77 \\
SH & 1.72 & 1.97 \\
Tropics & 2.77 & 1.00 \\
\hline
\end{tabular}

${ }^{\mathrm{a}} \mathrm{Unit}$ of measure is $\mathrm{MJ} \mathrm{m}^{-2}$ 
change in the global atmospheric observing system which took place in 1979 is considered. For computational reasons the experimental periods have been limited to three short periods.

[33] The overall finding in this paper is model dependent to some extent and therefore cannot be generalized. Experiments with other assimilation systems will give different results since it depends on model biases. Yet it should be possible to correct for artificial trends in the same way as done in the present study.

[34] Because of the concern about climate change and the need to better understand what occurs in the free atmosphere it is strongly recommended that more substantial studies be undertaken to try to better estimate climate trends for the last 50 years. With carefully designed experiments this will constitute a valuable complement to trend calculations from observational data on its own. We believe that this will require proper consideration of which observations to use in the reanalyses, as changes in the observing systems, of the kind which have taken place during the last 40 years, are likely to introduce artificial climate trends of similar magnitude as the real ones.

[35] Returning finally to the question in the title of this study an affirmative answer cannot be given, as the indications are that in its present form the ERA40 analyses are not suitable for long-term climate trend calculations. However, it is believed that there are ways forward as indicated in this study which in the longer term are likely to be successful. The study also stresses the difficulties in detecting long term trends in the atmosphere and major efforts along the lines indicated here are urgently needed.

[36] Acknowledgments. The authors wish to thank ECMWF and especially the ERA40 research team and the computer support staff for valuable assistance. The experiment has been undertaken in an ECMWF special project study.

\section{References}

Bengtsson, L., and J. Shukla (1988), Integration of space and in situ observations to study global climate change, Bull. Am. Meteorol. Soc., $69,1130-1143$

Bengtsson, L., K. I. Hodges, and S. Hagemann (2004), Sensitivity of re-analyses to the observing system: Determination of the global atmospheric circulation from reduced observations, Tellus, in press.
Christy, J. R., R. W. Spencer, and E. S. Lobi (1998), Analysis of the merging procedure for the MSU daily temperature time series, J Clim., 11, 2016-2041.

Christy, J. R., R. W. Spencer, and W. D. Braswell (2000), MSU tropospheric temperatures: Dataset construction and radiosonde comparison, J. Atmos. Oceanic. Technol., 17, 1153-1170.

Christy, J. R., R. W. Spencer, W. B. Norris, W. Braswell, and D. E. Parker (2003), Error estimates of version 5.0 of MSU-AMSU bulk atmospheric temperatures, J. Atmos. Oceanic. Technol., 20, 613-629.

Gibson, J. K., P. Kållberg, S. Uppala, A. Hernandez, A. Nomura, and E. Serrano (1997), ERA Description, Re-Anal. Proj. Rep. Ser., 1, 72 pp., Eur. Cent. for Medium-Range Weather Forecast., Reading, UK.

Goody, R., J. Anderson, T. Karl, R. B. Miller, G. North, J. Simpson, G. Stephens, and W. Washington (2002), Why monitor the climate?, Bull. Am. Meteorol. Soc., 83, 873-878.

Hagemann, S., L. Bengtsson, and G. Gendt (2003), On the determination of atmospheric water vapor from GPS measurements, J. Geophys. Res., 108(D21), 4678, doi:10.1029/2002JD003235.

Kalnay, E., and M. Cai (2003), Impact of urbanization and land-use change on climate, Nature, 423, 528-531.

Kalnay, E., et al. (1996), The NCEP/NCAR 40-Year Re-Analysis Project, Bull. Am. Meteorol. Soc., 77, 437-471.

Kistler, R., et al. (2001), The NCEP-NCAR 50-year reanalysis: Monthly means CD-ROM and documentation, Bull. Am. Meteorol. Soc., 82, $247-$ 268.

Miyakoda, K., J. Smagorinsky, R. F. Strickler, and G. D. Hembree (1969), Experimental extended predictions with a nine-level hemispheric model, Mon. Weather Rev., 97(1), 1-76.

Roeckner, E., et al. (2003), The atmospheric general circulation model ECHAM5, part 1, Model description, Rep. 349, Max-Planck-Inst. for Meteorol., Hamburg, Germany.

Schubert, S. D., R. B. Rood, and J. Pfaendtner (1993), An assimilated dataset for Earth science applications, Bull. Am. Meteorol. Soc., 74, $2331-2342$.

Simmons, A. J., and J. K. Gibson (2000), The ERA-40 Project Plan, ERA-40 Project Rep. Ser., 1, 63 pp., Eur. Cent. Medium-Range Weather Forecast., Reading, UK.

Stendel, M., and L. Bengtsson (1997), Toward monitoring the tropospheric temperature by means of a general circulation model, J. Geophys. Res., 102, 29,779-29,788.

Su, H., J. D. Neelin, and J. E. Meyerson (2003), Sensitivity of tropical temperature to sea surface temperature forcing, J. Clim., 16, 1281-1303.

Trenberth, K. E., T. R. Karl, and T. W. Spence (2002), The need for a systems approach to climate observations, Bull. Am. Meteorol. Soc., 83, $873-878$

Trenberth, K., A. Dai, R. M. Rasmussen, and D. B. Parsons (2003), The changing character of precipitation, Bull. Am. Meteorol. Soc., 84, $1205-$ 1217.

Vinnikov, K. Y., and N. C. Grody (2003), Global warming trend of mean tropospheric temperature observed by satellites, Science, 302, 269-272.

L. Bengtsson and S. Hagemann, Max-Planck-Institute for Meteorology, Bundesstrasse 55, D-20146 Hamburg, Germany. (bengtsson@dkrz.de)

K. I. Hodges, Environmental Systems Science Centre, Harry Pitt Building, Whiteknights, P.O. Box 238, Reading RG6 6AL, UK. 